\title{
Hydrogen Distribution and Explosion in Containment Building
}

\author{
Kweonha Park \\ Korea maritime and ocean university \\ 727, Taejong-ro, Yeongdo-gu, Busan 49112, Korea \\ khpark@kmou.ac.kr
}

\begin{abstract}
The hydrogen risk should be considered in severe accident strategies in nuclear power plants. This paper describes the analytical result of the hydrogen distribution and explosion after the failure takes place in a containment building. Hydrogen is accumulated on the top of the containment during the hydrogen release period. After the period, the released steam pushes down the hydrogen, and some amount of hydrogen is trapped among the compartments in the lower part of the containment. Long time after the accident the hydrogen slowly rises up to the top of the containment with temperature cooling down. During the process, there are many chances for hydrogen explosion. At the containment top, the hydrogen increases up to $55 \mathrm{vol} . \%$ and air is $45 \mathrm{vol} \%$ at 15 hours after the accident, which is the most dangerous state of hydrogen explosion. The hydrogen flame is developed slowly until 4 second after ignition, then the detonation is begun. The maximum explosion pressure reaches 75 bar which is the dangerous impact pressure which may destroy a containment building. At the containment bottom, the gas composition is 33 vol. $\%$ of hydrogen, 30 vol. $\%$ of steam and $35 \mathrm{vol} \%$ of air at 4 hours after the accident, which is the most dangerous state among the compartments at the bottom. The flame develops much faster than that at the top area, but the peak impact pressure is much lower than at the containment top.
\end{abstract}

Keywords: Hydrogen, Explosion, Containment, Distribution.

\section{Introduction}

As shown in Fukushima accident, all the designed emergency cooling measures failed under extreme or hypothetical conditions such as the chemical reaction of steam and strongly overheated zircaloy. That produced significant amounts of hydrogen [1]. This hydrogen would then be released into the containment through the breakage [2]. Without a counter measurement, flammable mixtures may then be formed and cause combustion that could threaten the integrity of the containment [3]. The hydrogen behaviour during hydrogen release was computed by using CFD code [4]. The potential risk of hydrogen gas is analysed up to 15 hours after the failure happened during a small-breakup-loss-of-coolant-accident [5].

In this study, the behaviour of hydrogen distribution is summarized in the area having a potential risk of explosion. Then the combustion and explosion in the places are analysed at the most dangerous conditions.

\section{Mathematical Model and Calculation Grids}

\subsection{Mathematical Model}

The trensport equations are given as general form,

$$
\frac{\partial}{\partial \mathrm{t}}(\rho \Phi)+\frac{\partial}{\partial \mathrm{x}_{\mathrm{j}}}\left(\rho \mathrm{u}_{\mathrm{i}} \Phi\right)-\frac{\partial}{\partial \mathrm{x}_{\mathrm{j}}}\left(\rho \Gamma_{\Phi} \frac{\partial}{\partial \mathrm{x}_{\mathrm{j}}}(\Phi)\right)=\mathrm{S}_{\Phi}
$$

where, $\Phi$ is the properties of mass, enthalpy, etc, and $\Gamma_{\Phi}$ is the difusivity of $\Phi$.

The momentum equation with tensor notation is given as,

$$
\frac{\partial}{\partial t}\left(\beta_{v} \rho u_{i}\right)+\frac{\partial}{\partial x_{j}}\left(\beta_{j} \rho u_{i} u_{j}\right)=-\beta_{v} \frac{\partial p}{\partial x_{i}}+\frac{\partial}{\partial x_{j}}\left(\beta_{j} \sigma_{i, j}\right)+F_{o, i}+\beta_{v} F_{w, i}+\beta_{v}\left(\rho-\rho_{0}\right) g_{i}
$$

where, $\beta_{\mathrm{v}}$ is the volume fraction of the ideal gas, $\rho$ is gas density, $\mathrm{u}_{\mathrm{i}}$ and $\mathrm{u}_{\mathrm{j}}$ are the velocities in the direction of $i$ and $\mathrm{j}$, respectively. $\mathrm{p}$ is pressure, and $\mathrm{F}_{\mathrm{w}, \mathrm{i}}$ rate of change in quantities of in Euler coordinate system.

Transient term is discretized with second order backward Euler scheme. It is second-order accurate in time, and given by 


$$
\frac{\partial}{\partial t} \int_{\mathcal{V}} \rho \emptyset d \boldsymbol{V}=\boldsymbol{V} \frac{1}{\Delta t}\left(\frac{3}{2}(\rho \emptyset)-2(\rho \emptyset)^{0}+\frac{1}{2}(\rho \emptyset)^{00}\right.
$$

Where ( $)^{0}$ and ( ) $)^{00}$ are the old and one more step old time level solution values.

The $k$ - $\omega$ based SST model is used on turbulent flow, which accounts for the transport of the turbulent shear stress and gives highly accurate predictions of the onset and the amount of flow separation under adverse pressure gradients. It solves two transport equations, one for the turbulent kinetic energy, and one for the turbulent frequency. The equations are given as

$$
\begin{gathered}
\frac{\partial(\rho k)}{\partial t}+\frac{\partial\left(\rho U_{j} k\right)}{\partial x_{j}}=\frac{\partial}{\partial x_{j}}\left[\left(\mu+\frac{\mu_{t}}{\sigma_{k}}\right) \frac{\partial k}{\partial x_{j}}\right]+P_{k}-\beta^{\prime} \rho k w+P_{k b} \\
\frac{\partial(\rho w)}{\partial t}+\frac{\partial\left(\rho U_{j} w\right)}{\partial x_{j}}=\frac{\partial}{\partial x_{j}}\left[\left(\mu+\frac{\mu t}{\sigma w}\right) \frac{\partial w}{\partial x_{j}}\right]+\alpha \frac{w}{k} P_{k}-\beta^{\prime} \rho \omega^{2}+P_{w b}
\end{gathered}
$$

Where, $\mathrm{k}$ is the turbulent kinetic energy, $w$ is the turbulent frequency, $\mu$ is viscosity, $\mu_{t}$ is turbulent viscosity, and $t$ is time. For buoyancy calculations, a source term is added to the momentum equation as follows:

$$
\mathrm{S}_{\text {buou }}=\left(\rho-\rho_{\text {ref }}\right) g
$$

Where $\rho$ is the density of a gas, $\rho_{\text {ref }}$ is density at the reference location, and $g$ is the gravity acceleration.

\subsection{Geometry and Grids}

Fig.1 and Fig.2 show the inner shape and the calculations grids of the containment building of the APR1400 nuclear plant respectively. The APR1400 is an evolutionary pressurized water reactor with its origins in the CE System 80+ design. The 1,400 MW APR1400 nuclear reactor design is currently under operation at Shin Kori 3\&4 and Shin Hanul in Korea. The facilities to mitigate severe accidents are designed to meet the procedural requirements and criteria of the U.S. NRC regulations. The diameter and height are $22.86 \mathrm{~m}$ and $79.4 \mathrm{~m}$, respectively. The lower part of the containment is composed of some compartments and pipe lines. The in-containment refuelling water storage tank (IRWST) is placed on the bottom as annular shape, which depth is $3.5 \mathrm{~m}$. The reactor vessel is located in the middle and two steam generators and cooler pumps are placed to be symmetrical. Compartment panels are located among the parts, and the parts are connected with pressurized tubes. The failure locations are assumed on the pressurized tube surface. The total number of grids is 2,700,000 and the grids are generated using NX 7.5 and ICEM-CFD codes. The grids are densely generated near the failure range to reduce error from high velocity and high pressure gradient. Fig.3 shows monitoring points of hydrogen concentrations which data is used to calculate explosions.

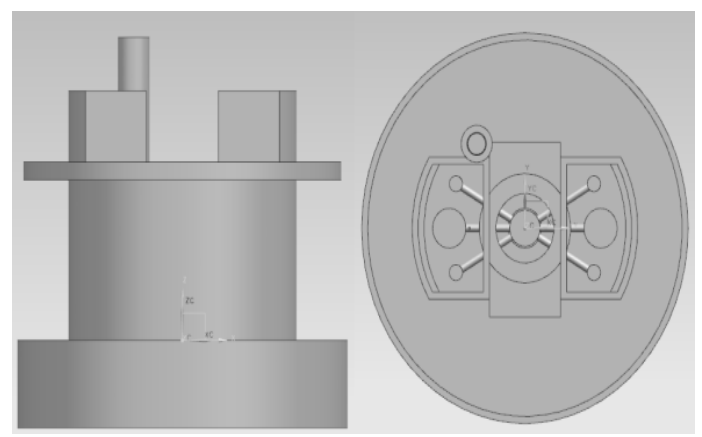

Fig. 1: Inner shape of the containment building of the APR1400 nuclear plant. 


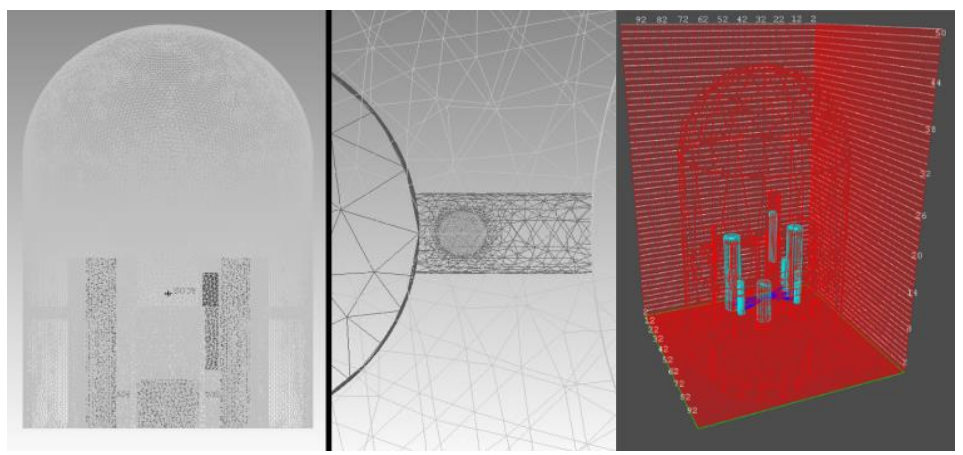

Fig. 2: Calculation grids for hydrogen distribution and explosion.

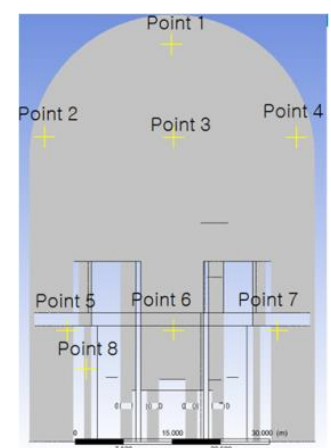

Fig. 3: Measuring points.

\section{Result and Discussion}

\subsection{Hydrogen Distribution and Explosion at Containment Top}

Fig. 4 shows gas volume fractions and their variation with time from the accident at the point 1 given in Fig. 3. The flammability limits based on the volume percent of hydrogen are 4.0 and 75.0. The limits of detonability of hydrogen in air are 18.3 to 59 percent by volume. The gas composition was 75 vol.\% of steam, 15 vol.\% of hydrogen and $15 \mathrm{vol} . \%$ of air at 6000 s. Soon after the location is filled with over 90 vol. $\%$ of steam followed by rapid reduction of hydrogen release. The hydrogen remains less than 5\% until 20000s, and then increased slowly. Air concentration increases continuously, while steam decreases. The hydrogen increases up to 55 vol.\% and air is 45 vol.\% at 54000s, as shown in Fig 5, which is the most dangerous state of hydrogen explosion. Therefore, the combustion and explosion analysis was conducted at the condition of 54000s. Fig. 6 shows combustion products distributions at the point 1, and Fig. 7 shows the pressure variation during explosion. The figures show the combustion behaviour from the start of ignition. The hydrogen flame is developed slowly until $4 \mathrm{~s}$ after ignition, then the detonation is begun. The maximum explosion pressure reaches 75 barg which is the dangerous impact pressure destroying a containment wall. 


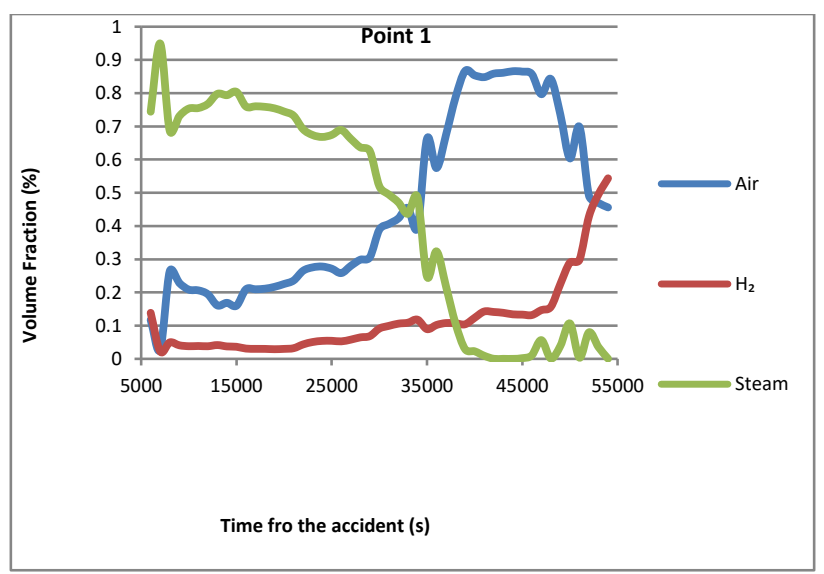

Fig. 4: Gas volume fractions with time at Point 1.

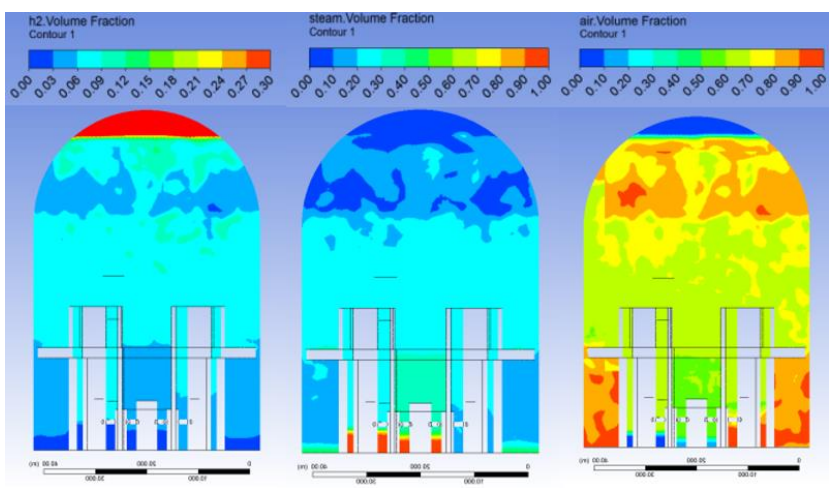

Fig. 5: Distribution of hydrogen, steam and air at 54000s.

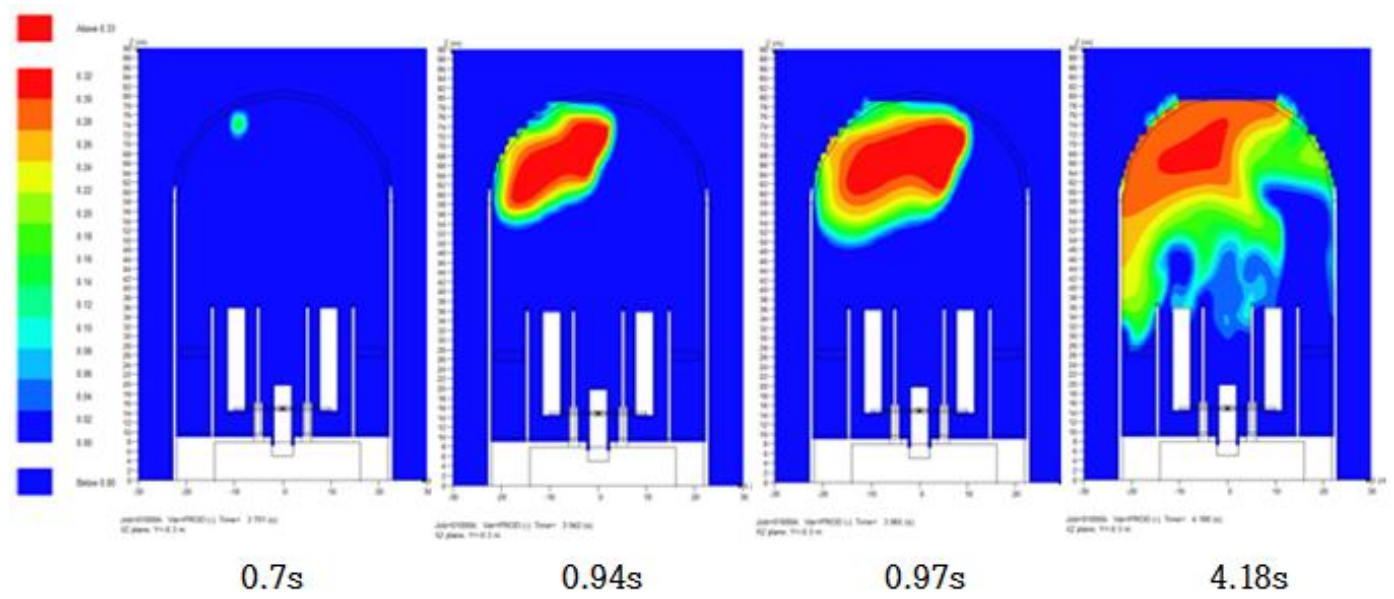

Fig. 6: Combustion Products at Point 1. 


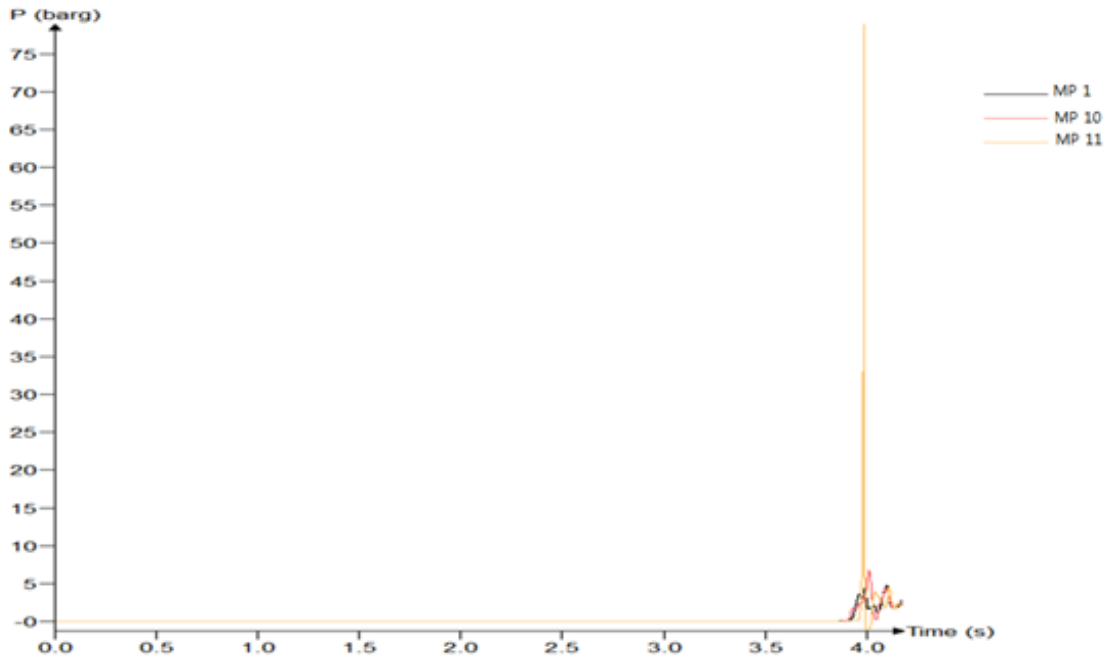

Fig. 7: Pressure variation with time from ignition.

\subsection{Hydrogen Distribution and Explosion at Containment Bottom}

Fig. 8 shows gas volume fractions and their variation with time from the accident at the point 7 given in Fig. 3. The gas composition became $33 \mathrm{vol} \%$ of hydrogen, $30 \mathrm{vol} \%$ of steam and 35vol\% of air at $14000 \mathrm{~s}$ as shown in Fig. 9. Hydrogen concentration remained at very low level during the other period which has no explosion risk. At the condition of $14000 \mathrm{~s}$ after the failure begun, the hydrogen explosion analysed and the results is shown in Fig. 10 and 11. The products or flame developed much faster than those at top area, and explosion also happened and peak impact pressure reached 25 barg at $0.4 \mathrm{~s}$ after ignition start.

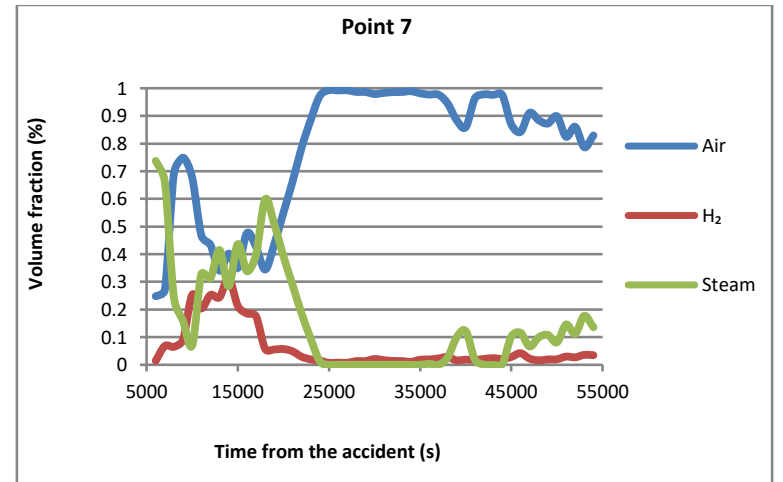

Fig. 8: Gas volume fractions with time at Point 7.

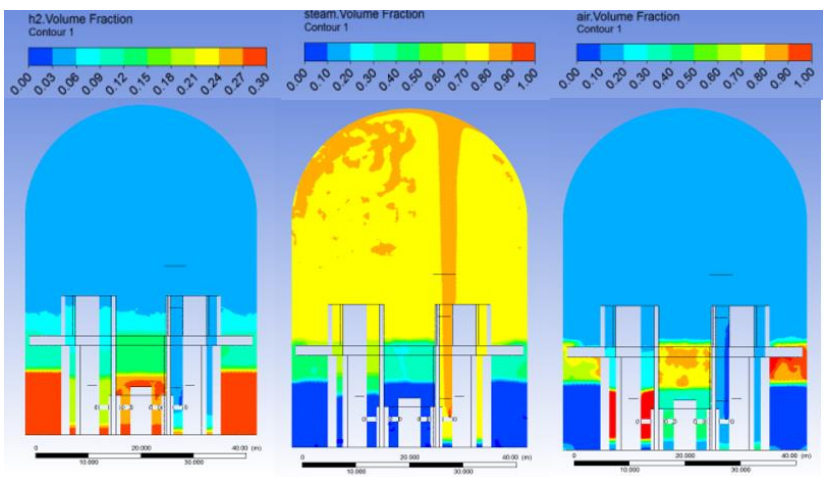

Fig. 9: Distribution of hydrogen, steam and air at 14000s. 


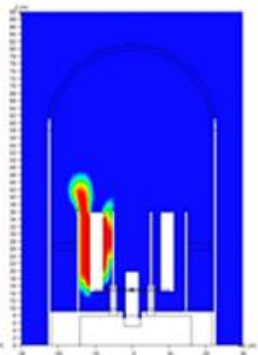

$0.1 \mathrm{~s}$

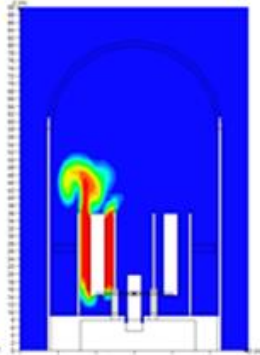

$=-\cdots$

$0.4 \mathrm{~s}$

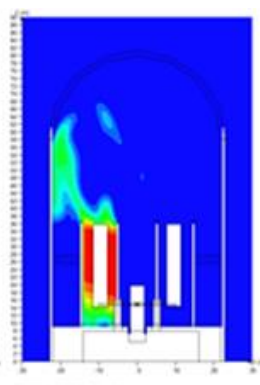

$0.93 \mathrm{~s}$

Fig. 10: Combustion Products at Point 7.

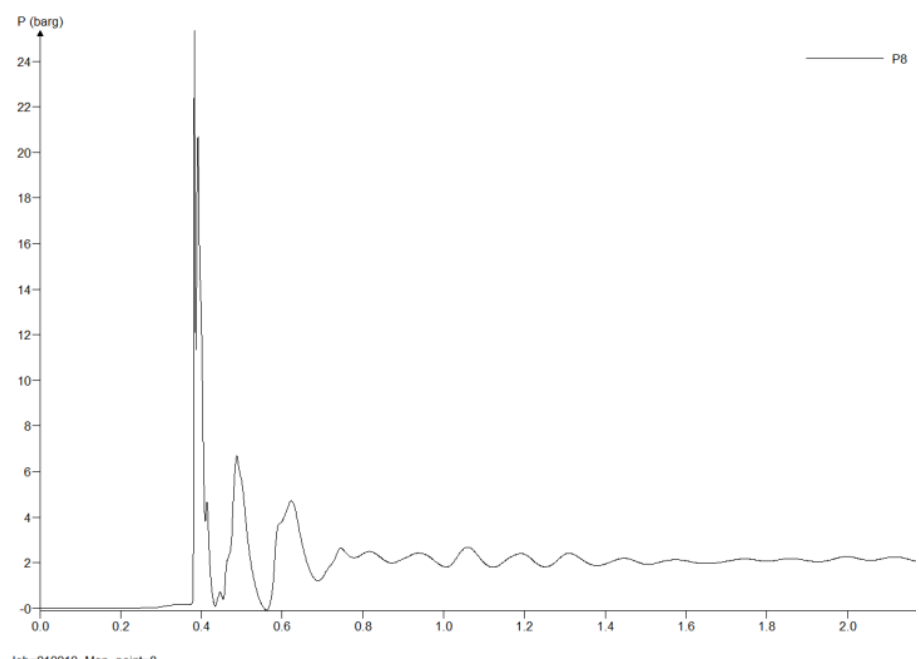

Fig. 11: Pressure variation with time from ignition.

\section{Conclusion}

This study analyses hydrogen behaviour and explosion risk in the containment. The simulation lasted for 15 hours to observe the process changes of hydrogen explosion in the containment when a SBLOCA occurred.

Hydrogen distribution and explosion at the containment top; The hydrogen increases up to 55 vol. $\%$ and air is 45 vol. $\%$ at 54000s, which is the most dangerous state of hydrogen explosion. Therefore, the combustion and explosion analysis was conducted at the condition of 54000s. The result shows the hydrogen flame is developed slowly until $4 \mathrm{~s}$ after ignition, then the detonation is begun. The maximum explosion pressure reaches 75 barg which is the dangerous impact pressure destroying a containment wall.

Hydrogen distribution and explosion at the containment bottom; The gas composition is 33 vol.\% of hydrogen, 30 vol. $\%$ of steam and $35 \mathrm{vol} \%$ of air at $14000 \mathrm{~s}$, which is the most dangerous state of hydrogen explosion. Hydrogen concentration remained at very low level during the other period which has no explosion risk. At the condition of 14000s, the hydrogen explosion analysed and the results shows the products or flame developed much faster than those at the top area, and explosion also happened and peak impact pressure reached 25 barg at $0.4 \mathrm{~s}$ after ignition start.

\section{References}

[1] J. Xiao and J. R. Travis, "How critical is turbulence modeling in gas distribution simulations of large-scale complex nuclear reactor containment?," Annals of Nuclear Energy, vol. 56, pp. 227-242, 2013.

[2] P. Apanasevich, P. Coste, B. Niceno, C. Heib and D. Lucas, "Comparison of CFD simulations on two-phase Pressurized Thermal Shock scenarios," Nuclear Engineering and Design, vol. 266, pp. 112-128, 2014.

[3] S. Chatzidakis and A. Ikonomopoulos, "Phenomenological Investigation of loss of coolant accident in a research reactor facility,” Nuclear Engineering and Design, vol. 256, pp. 341-349, 2013. 
[4] K. Park and K. H. Bae, "Hydrogen concentration variation and examination of PAR installation in reactor containment building during hydrogen release from different direction failure places," Nuclear Engineering and Design, vol. 278, pp. 229-238, 2014.

[5] K. Park and C. L. Khor, "Consideration on hydrogen explosion scenario in APR 1400containment building during small breakup loss of coolant accident," Nuclear Engineering and Design, vol. 293, pp. 458-467, 2015. 